\title{
Erratum
}

Journal of Applied Electrochemistry (2005) 35:1321-1329

(C) Springer 2005

DOI 10.1007/s10800-005-9064-0

\section{Studies on electrochemical disinfectant production using anodes containing $\mathrm{RuO}_{2}$}

M. E. H. BERGMANN ${ }^{1, *}$ and A. S. KOPARAL ${ }^{2}$

${ }^{1}$ Department of Electroengineering, Anhalt University of Applied Sciences, 06366, Koethen, Germany

${ }^{2}$ Department of Environmental Engineering, Anadolu University, 26470, Eskisehir, Turkey

(*author for correspondence E-mail: bergmann@et.hs-anhalt.de)

Due to an unfortunate mistake in the typesetting process the wrong Figures $8-10$ were inserted in the abovementioned paper. The correct figures are provided below.

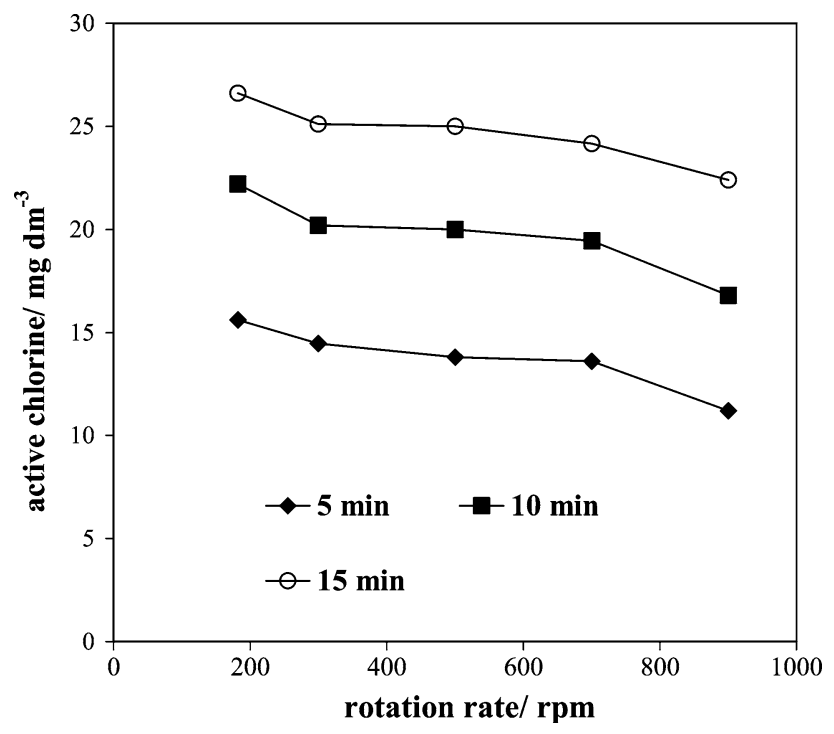

Fig. 8

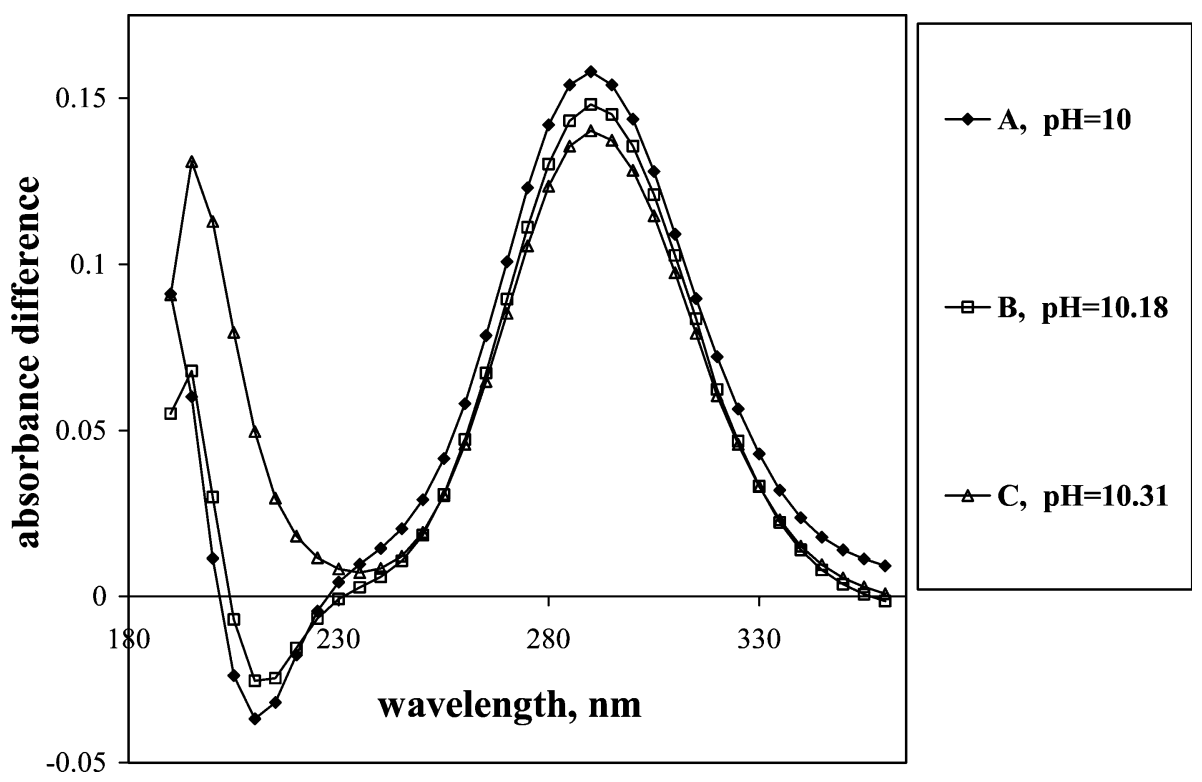

Fig. 9 


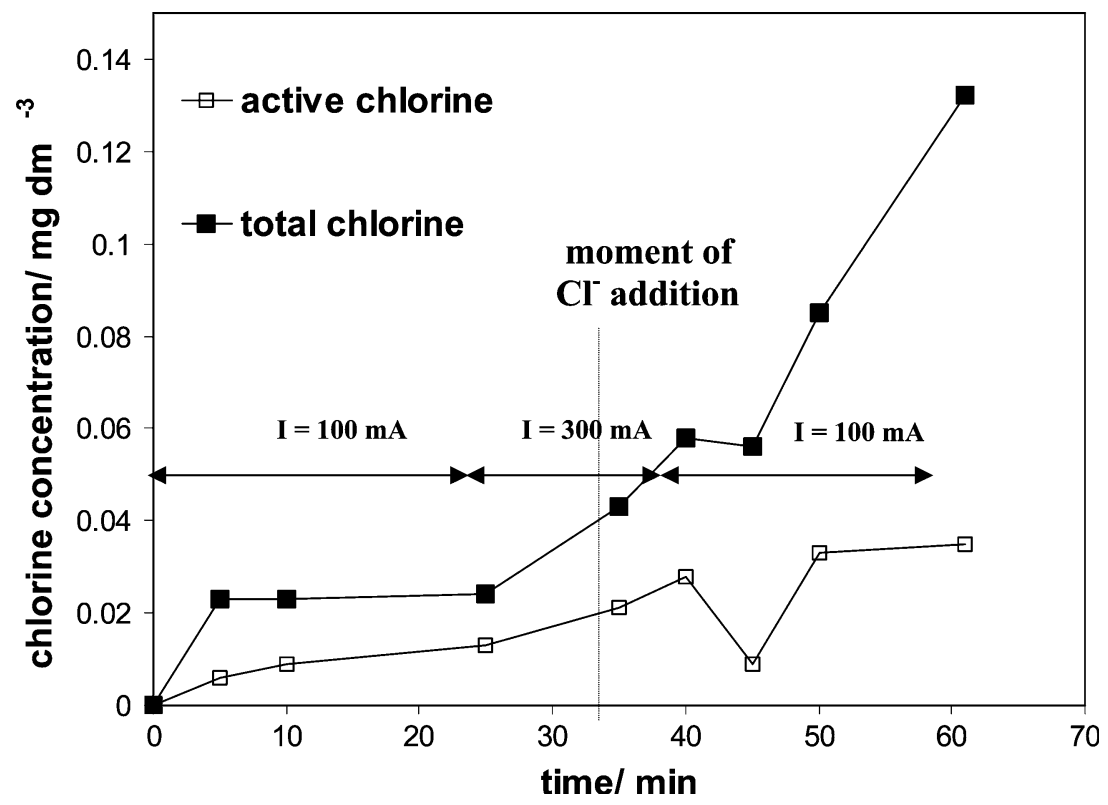

Fig. 10 